\title{
Directness and Appropriateness - Complaints Perceived by English Users of Different Ages in Taiwan
}

\author{
Chi-yin Hong \\ Department of Applied English, Kun Shan University, Tainan, Taiwan (R.O.C.) \\ Correspondence: Chi-yin Hong, Department of Applied English, Kun Shan University, Tainan, Taiwan (R.O.C.)
}

Tel: 886-6-272-7175 ext 287. E-mail: cathyhong0419@hotmail.com

Received: August 5, 2013 Accepted: August 19, 2013 Available online: September 14, 2013

doi:10.11114/smc.v1i2.195 URL: http://dx.doi.org/10.11114/smc.v1i2.195

\begin{abstract}
This study explores the complaint strategies preferred by different age groups of English users in Taiwan. Seventy-eight subjects participated in this study, making up three groups: the teenager (TA) group, the young adult (YA) group, and the middle-aged (MA) group. The instrument was a multiple-choice task, which consisted of twenty scenarios, with the options representing six strategies: hints, disapproval, requests for repair, explicit complaints, accusations, and silence. Each of the two contextual variables, status and social distance, was involved in the scenarios for investigation of its effects on the subjects' strategy selection. The results reveal age-graded differences in the MA group's lowest severity level among the three groups, whereas no obvious differences were found between the YA and TA groups. The effects of status and social distance on the YA and TA groups were similar, but the MA group exhibited different tendencies. Possible influences from age and employment status on the perceptions and strategy selection are discussed.
\end{abstract}

Keywords: complaint, age, status, social distance

\section{Introduction}

Speech acts have been a topic that attracts much research attention, and many studies (e.g., Blum-kulka, 1982; Cohen \& Shively, 2007; DeCapua, 1988; Olshtain \& Weinbach, 1993; Trosborg, 1995; Warga \& Scholmeberger, 2007) have examined pragmatic competence, i.e., ability to relate utterances to the communicative goals of the language user and to the features of the language use setting (Bachman \& Palmer, 1996) in learners' interlanguage system. Whereas many of the previous studies investigated the relationship between learners' speech behaviors and contextual variables, such as the addressee's status, social distance, and gender, few addressed the age-grading effects, i.e., using the language appropriate for the speaker's age group (Wardhaugh, 2002), on their perceptions of appropriate behaviors and thus leave a niche for further research. As cross-cultural communication grows in popularity, young people are assumed to be more likely to be engaged in interactions with speakers from different cultural backgrounds than older generations. However, their speech styles are often characterized as casual and direct and may therefore cause misinterpretations. To explore whether this tendency can be found in English users' perceptions, a better understanding of how users of different age groups perceive appropriate behaviors in different contexts, face-threatening acts such as complaints in particular, is needed. [1]

\subsection{Literature Review}

\subsubsection{Complaints}

Complaints are a kind of speech act in which a speaker expresses disappointment or a grievance (Clyne, 1994). They are usually part of complex interactional sequences, beginning with an expression of disappointment, either explicit or implicit, with the complainee or their behavior. They may also include moral judgments and directives in the forms of requests for action, orders, or threats to prevent the repetition of the offensive act and offer the complainee an opportunity to repair the damages s/he has caused. Edmondson-House (1981) has pointed out that in making a complaint, "a speaker potentially disputes, challenges, or bluntly denies the social competence of the complainee" (pp. 145). As complaints threaten the complainee's positive face, which refers to the need to be appreciated and approved of by others (Brown \& Levinson, 1987), they often cause confrontations between the 
complainer and the complainee.

Due to the face-threatening nature of complaints, complainers may need to go through comprehensive thought processes to select appropriate strategies to fit the context. Olshtain and Weinbach (1993) established a model, which consists of the following three junctures, for considerations in making complaints. Firstly, the complainer can decide to avoid the act though s/he feels frustrated and annoyed. S/he can also choose to complain and then moves on to the second juncture: to carry out the act "off record" or "on record". If the complainer realizes the complaint "off record", s/he gives hints to the complainee and wards off direct confrontations. On the other hand, if an "on-record" complaint is about to be produced, the complainer goes on to the third juncture: to express the censure on record with or without redress, i.e., compensation or modifications. Without redress, the censure can be a directive imperative and might lead to a threat or an insult. However, if the complainer employs redress as part of the complaint, s/he can select a strategy that addresses positive politeness, which shows mutual concern and understanding, or negative politeness, with the use of a mitigated expression to show deference.

Numerous studies examined language learners' complaints (e.g., DeCapua, 1988; Lee, 1999; Murphy \& Neu, 1995; Trosborg, 1995; Shea, 2003) and found that the strategies learners preferred differed according to their cultural backgrounds and English proficiency. Learners also tended to be more direct than native speakers and appeared to be unable to appropriately adjust their speech behaviors to the contexts which might involve various factors, discussed as follows.

\subsubsection{Contextual Factors and Directness of Complaints}

Complaints can be direct and indirect, with direct complaints being considered more face-threatening. The complainer's choice of directness level is influenced by contextual variables, such as status, social distance, age, gender, and the formality of the context, and this study only addresses the first three. The difference in status between a speaker and an addressee can be thought of as vertical distance that reflects the power of one over the other (Hudson, Detmer, \& Brown, 1995) and affects the degree to which the speaker can impose will on the addressee. In general, the speaker's speech behavior towards a higher-ranked addressee tends to be more polite and more indirect than towards a status equal since the amount of optionality and indirectness needed in an imposition increases with the addressee's status (Leech, 1983).

In Chinese culture, where the participants of this study came from, status difference is especially important because of the Chinese tradition of feudal hierarchy and Confucian political philosophy, which emphasizes respect for and subordination to authorities (Oliver, 1971). Traditionally, Chinese people have expressed respect and subordination by devaluing themselves, and this has influenced their concept of polite behavior. However, Shih (1999) has pointed out that in recent years, the authority of parents and teachers seems to have diminished, even though the education system still stresses the importance of deference to parents. This discrepancy suggests that Chinese people of different generations might have different views about appropriate speech styles toward those of higher status.

Another variable, social distance, refers to the degree of familiarity between the conversation participants. It is related to their in-group or out-group membership, which reflects their affiliation and solidarity (Hudson et al., 1995). Conversation participants who are members of a common social group are closer in social distance than those who do not belong to the same group. Social distance determines the speaker's speech behavior-a polite, indirect style would be preferred as social distance between conversation participants increases (Leech, 1983). However, Wolfson (1988) has proposed a different view, known as "the Bulge Theory," which claims that speakers behave similarly in interactions with intimates and those with strangers because they are certain about the relationship and know what to expect in the interaction. Nonetheless, the relationship with acquaintances, whose social distance is in between, is relatively obscure. Speakers thus have to be especially careful in the negotiation of meaning to signal solidarity (Brown \& Gilman, 1960) and to avoid confrontations (D’Amico-Reisner, 1985), leading to quite different speech styles between their interactions with intimates and strangers.

A third variable that may influence the way a speaker talks is age, and the effects can be particularly obvious with adolescents, who tend to favor the use of vernacular or non-standard variants to construct identities independent of their elders (Eckert, 1997). The influence of peers can also drive adolescents to use non-standard variants as solidarity markers and may result in innovative language that is different from other age groups' use (Tagliamonte, 2005). However, after the language learners grow older and enter employment, their speech styles may change. Research has shown that adults are likely to be more conservative than adolescents in speech styles due to the pressure to use standard language in the workplace. In contrast, elderly, retired speakers tend to use more non-standard variants than other adults, possibly because their disengagement from the marketplace brings 
less concern with standard language norms (Chambers \& Trudgill, 1980; Horvath, 1985; Labov, 1966; Trudgill, 1974).

Some previous studies examined how status and social distance influenced complaints (e.g., Lee, 1999; Olshtain and Weinbach, 1993; Trosborg, 1995; Shea, 2003), but few explored the effects of age, mostly centering on teenagers. Marriott (1995) and Regan (1995) observed Australian high-school learners of Japanese (age 15-18) and college-aged Irish learners of French (19-21) and found that both groups overused plain styles, which were too colloquial to differentiate formal and informal registers. They concluded that the strong peer influence on teenagers contributed to age-graded L2 use appropriate in casual peer interaction but not in formal situations. Finally, Chang's (2006) study investigated the role of age in Chinese speakers' L1 complaint styles. With participants from four age groups $(13,16,19$, and 23 years), Chang found that the older the subjects were, the more indirectly they complained.

To sum up, existing studies on the effects of age have been limited, and no comparisons of speech behaviors between teenage subjects and other age groups can be offered. Further, research into the age effects on speech acts by Chinese users of English is still lacking. Thus, this study aims to explore the age-grading tendencies in perceptions of appropriate complaint strategies through English users of three different age groups- middle-aged adults, young adults, and teenagers in Taiwan, an English-as-a foreign-language (EFL) setting, and the research questions of this study are:

1. What are the complaint strategies perceived as appropriate by middle-aged adults, young adults, and teenagers?

2. What are the three age groups' complaint strategies in reaction to an upgraded response from the addressee?

3. Are there significant differences among the perceptions of appropriate complaint strategies of the three age groups?

4. How do two contextual variables, status and social distance, influence the three age groups' strategy perceptions?

\section{Methodology}

\subsection{Subjects}

Seventy-eight subjects participated in this study, drawn from three age groups: teenagers (15-17 years old), young adults (21-25 years old), and middle-aged adults (31-40 years old). Each age group included twenty-six participants, recruited from schools in Taiwan, and they had English proficiency of an intermediate level or higher.[2] Subjects in the teenager group were first-year senior high school students, and those in the young adult group were junior or senior English majors in college. The middle-aged participants were English teachers.

\subsection{Instrument}

A multiple-choice task was used to collect data. It included twenty scenarios, each consisting of a description of a situation, followed by options of utterances for the subjects to select from. The scenario also offered an upgrader produced by the addressee being complained to and required the subjects to re-choose an option to respond. One of the two contextual variables, status and social distance, was involved in each scenario. The characters in the scenarios stood for addressees of varying status types and degrees of distance, such as teachers/employers, classmates/ co-workers, siblings, neighbors, and unknown students/strangers. [3]

\section{Scenario 1}

Your teacher always talks very fast in class, and you often do not understand what s/he talks about. One day s/he talks very fast again; you are upset and tell him: “

a. Some of us are having some problems in class.

b. This class is really frustrating.

c. __ Could you please talk slowly in class?

d. __ I think you talk too fast in class!

e. ___ If you keep talking so fast, I'll tell the chairperson!

f. _ (Silence)

※ __ is the best choice for you in this situation because

※ If your teacher responds, "You should have known this would happen in class; it's your problem if you can't understand," then your response is most likely to be first response is (f) silence.) (choose from a to f; write $\mathbf{X}$ here if your 
As shown above, there were six options in each scenario, representing different complaint strategies: (1) hints, (2) disapproval, (3) requests for repair, (4) explicit complaints, (5) accusations and threats, and (6) opting out, i.e., silence. With the exception of "opting out," the degree of severity of the five strategies was assumed to increase from (1) to (5). The options were designed by the researcher and a native English speaker, who was an experienced English teacher. If the subjects selected (f) silence as their initial strategy, there would not be an opportunity for an addressee's upgrader to occur, so the second strategy would be counted as "no response," which was not viewed as a complaint strategy and had a different meaning from "opting out" in this study.

The data were processed statistically with SPSS 12 . Chi-square analyses were conducted to determine whether the preferred strategies significantly differed among the three age groups. The effects of status and social distance on the subjects' strategy choices were also examined with Chi-square analyses.

\section{Results and Discussion}

\subsection{Overall Selection of Complaint Strategies}

Middle-aged (MA), young adult (YA), and teenager (TA) groups selected all of the six strategies, and the total amounts of the strategies they chose were similar, ranging from 960 to 975 . As Table 1 shows, the three groups all preferred requests for repair (MA: 26\%; YA: 24\%; TA: 23\%) over the other complaint strategies. The three groups also showed similar patterns when their strategy selection was further divided into the initiative (the first complaint strategy) and the response (the responsive strategy to the upgrader). All three groups chose requests for repair most frequently as their initiative (MA: 41\%; YA: 39\%; TA: 37\%) and tended to use severer strategies as their response to the upgrader, with the MA group opting for explicit complaints (22\%) and the YA (31\%) and TA (30\%) groups favoring accusations.

Chi-square analyses demonstrate that there were significant differences among the three groups' overall selection of strategies $\left(\chi^{2}=43.940, p<.001\right)$, with the main difference being between the MA group and the other two groups. Both the YA $(\mathrm{p}<.001)$ and TA $(\mathrm{p}<.01)$ groups chose accusations significantly more often than the MA subjects, who opted for hints (MA*YA: $\mathrm{p}<.001 ; \mathrm{MA} * \mathrm{TA}: \mathrm{p}<.01)$ more frequently.

Table 1. Percentages of the Three Groups' Complaint Strategies

\begin{tabular}{lccccccccc}
\hline & & MA & & & YA & & \multicolumn{3}{c}{ TA } \\
& Initiative & Response & SUM & Initiative & Response & SUM & Initiative & Response & SUM \\
\hline Hint & 106 & 54 & 160 & 50 & 35 & 85 & 70 & 37 & 107 \\
& $(20 \%)$ & $(12 \%)$ & $(17 \%)$ & $(10 \%)$ & $(8 \%)$ & $(9 \%)$ & $(13 \%)$ & $(8 \%)$ & $(11 \%)$ \\
Disapproval & 46 & 91 & 137 & 55 & 88 & 143 & 55 & 92 & 147 \\
& $(9 \%)$ & $(20 \%)$ & $(14 \%)$ & $(11 \%)$ & $(19 \%)$ & $(15 \%)$ & $(11 \%)$ & $(21 \%)$ & $(15 \%)$ \\
Request & 213 & 38 & 251 & 204 & 33 & 237 & 192 & 30 & 222 \\
& $(41 \%)$ & $(8 \%)$ & $(26 \%)$ & $(39 \%)$ & $(7 \%)$ & $(24 \%)$ & $(37 \%)$ & $(7 \%)$ & $(23 \%)$ \\
Explicit & 69 & 97 & 166 & 116 & 74 & 190 & 96 & 77 & 173 \\
complaint & $(13 \%)$ & $(22 \%)$ & $(17 \%)$ & $(22 \%)$ & $(16 \%)$ & $(19 \%)$ & $(18 \%)$ & $(18 \%)$ & $(18 \%)$ \\
Accusation & 15 & 95 & 110 & 30 & 143 & 173 & 27 & 131 & 158 \\
& $(3 \%)$ & $(21 \%)$ & $(11 \%)$ & $(6 \%)$ & $(31 \%)$ & $(18 \%)$ & $(5 \%)$ & $(30 \%)$ & $(16 \%)$ \\
Opting out & 71 & 74 & 145 & 65 & 82 & 147 & 80 & 73 & 153 \\
& $(14 \%)$ & $(16 \%)$ & $(15 \%)$ & $(13 \%)$ & $(18 \%)$ & $(15 \%)$ & $(15 \%)$ & $(17 \%)$ & $(16 \%)$ \\
No response & $\mathrm{N} / \mathrm{A}$ & 71 & 71 & $\mathrm{~N} / \mathrm{A}$ & 65 & 65 & $\mathrm{~N} / \mathrm{A}$ & 80 & 80 \\
Total & 520 & 449 & 969 & 520 & 455 & 975 & 520 & 440 & 960 \\
& $(100 \%)$ & $(100 \%)$ & $(100 \%)$ & $(100 \%)$ & $(100 \%)$ & $(100 \%)$ & $(100 \%)$ & $(100 \%)$ & $(100 \%)$ \\
\hline
\end{tabular}

The subjects' reasons for preferring requests for repair were similar but with different priorities, as shown in Table 2. Nearly half (45\%) of the MA subjects indicated indirectness and politeness as their main reason for choosing this strategy whereas $48 \%$ of the YA subjects reported directness. The TA subjects were also similar, with more balanced preferences for politeness (39\%) and directness (32\%). It appeared that the MA subjects were concerned about politeness and face threats that might be caused to the addressee, while the YA subjects preferred to let the addressee know what they should do in that situation. Similarly, the TA subjects cared about politeness and also considered requests for repair an effective strategy for letting the addressee know the expected follow-up actions. On the other hand, since the MA subjects used hints significantly more often that the other two groups, their reasons were analyzed in Table 3, which indicates that the MA subjects regarded this 
indirect strategy as effective enough to let the addressee know the speaker's feelings.

To sum up, both the quantitative and qualitative analyses support YA and TA groups' tendency to express disapproval more straightforward and thus were severer in complaints than the MA group. This tendency corresponds to Chang's (2006) claim that older subjects are more likely to use indirect strategies than the younger, probably because older speakers are inclined to be more well-rounded in interpersonal relationships and prefer reserved, indirect expressions even when they are upset. This tendency can also be explained from Lu and Kao (2002), who have pointed out that in Taiwan, the older generation (parents) retains more traditional collectivist values, which emphasize the community value of "we" over the individualism of "I" by showing concern to the face of people from the same community, than the younger generation, and thus displays the correlation between generational, age differences and cultural values. These two orientations were proposed by Hofstede (1984) in his description of cultural differences underlying Chinese and Western values, with collectivism being the Chinese value and individualism being Western, and now the cultural inclinations appear to be reflected by speakers of different age groups. In contrast, the YA and TA groups seemed to be relatively egocentric as they tended to express their own feelings and let the addressees know what they should do. As a result, they tended to be individualist-oriented, stressing "I" over "we". This study indicates that whereas the MA subjects seemed to stick to traditional Chinese values, the YA and TA subjects were slightly inclined to think and behave in a more western style. On the other hand, the result may also bolster Tagliamonte's (2005) perspective on adolescents' innovative language use, which can be further extended to young adults' behavioral patterns and relative openness to new values in comparison with their MA counterparts.

Table 2. Reasons Why the Subjects Preferred Requests for Repair

\begin{tabular}{llc}
\hline Group & \multicolumn{1}{c}{ Reason } & $\begin{array}{c}\text { Number } \\
\text { (percentage) }\end{array}$ \\
\cline { 2 - 2 } & It is polite and shows respect. & $72(45 \%)$ \\
It states the wish. & $37(23 \%)$ \\
MA It lets the addressee know the situation, how I felt, and what to do. & $22(14 \%)$ \\
It is direct, clear, and effective. & $12(8 \%)$ \\
Others & $17(10 \%)$ \\
Total & $160(100 \%)$ \\
\hline It lets the addressee know the situation, how I felt, and what to do. & $86(48 \%)$ \\
It is polite and shows respect. & $57(31 \%)$ \\
It states the wish. & $18(10 \%)$ \\
It is direct, clear, and effective. & $3(2 \%)$ \\
Others & $17(9 \%)$ \\
Total & $181(100 \%)$ \\
\hline & It is polite and shows respect. & $60(39 \%)$ \\
It lets the addressee know the situation, how I felt, and what to do. & $48(32 \%)$ \\
TA It states the wish. & $14(9 \%)$ \\
It is direct, clear, and effective. & $4(3 \%)$ \\
Others & $26(17 \%)$ \\
Total & $152(100 \%)$ \\
\hline
\end{tabular}

Note. This table summarizes the reasons provided by the subjects who did so.

Table 3. Reasons Why the MA Subjects Preferred Hints

\begin{tabular}{lc}
\hline \multicolumn{1}{c}{ Reason } & $\begin{array}{c}\text { Number } \\
\text { (percentage) }\end{array}$ \\
\hline It is indirect, polite, and least face-threatening. & $22(25 \%)$ \\
It lets the addressee know the situation and how I felt. & $39(43 \%)$ \\
It is obvious enough to let the addressee know what I mean. & $12(13 \%)$ \\
Things like that happen often, and that person might have a reason. & $6(7 \%)$ \\
Others & $11(9 \%)$ \\
Total & $90(100 \%)$ \\
\hline
\end{tabular}

Another explanation can be derived from research conducted by Horvath (1985), Labov (1966), and Trudgill (1974), with the claim that adults are more conservative in speech styles than adolescents due to the pressure to 
use standard language in the workplace. It is likely that pressure from the workplace not only influences the language forms that adults use but also how they use the language. Because employees view cooperation as essential in a workplace, they tend to be more concerned about one another's face so as to conduct face-threatening acts with care. This could be the reason why the MA subjects in this study, who have been in the workplace for some time, used more indirect complaint strategies than the YA and TA subjects, who were still students.

\subsection{Social Status and Complaint Strategies}

In addition to overall tendencies in complaint strategies, this study also investigated whether the relative social status of speaker and addressee was associated with the subjects' strategy selection. Table 4 shows that status did appear to play a role in the middle-aged (MA) group's choice of complaint strategies $\left(\chi^{2}=15.780, p<.01\right)$, as indicated by this group's most frequent choice of requests for repair as the most appropriate strategy for both superiors (24\%) and status equals (22\%). They also preferred them as the initiative (37\% and $38 \%)$ to the other strategies. However, while the MA subjects chose explicit complaints (24\%) and opting out (24\%) with equal frequency as a response to the upgrader produced by the superior, they employed explicit complaints (29\%) most frequently with status equals. In addition, the statistical difference was found in the MA subjects' use of accusations, which they utilized towards status equals more often. In other words, they tended to be severer towards status equals than towards superiors.

Table 4. Raw Number, Percentage, and Chi-square Value of the Three Groups' Strategy Selection in Scenarios Involving Addressees of Two Status Types

\begin{tabular}{ccccccccl}
\hline \multirow{2}{*}{ Group } & Strategy & \multicolumn{7}{c}{$(=\mathrm{P})$} \\
\cline { 2 - 8 } & Initiative & Response & SUM & Initiative & Response & SUM & Chi-square \\
\hline \multirow{6}{*}{ MA } & $26(25 \%)$ & $17(20 \%)$ & $43(23 \%)$ & $28(27 \%)$ & $10(12 \%)$ & $38(20 \%)$ & $\chi^{2}=.309$ \\
& S2 & $10(10 \%)$ & $18(21 \%)$ & $28(15 \%)$ & $5(5 \%)$ & $15(18 \%)$ & $20(11 \%)$ & $\chi^{2}=1.333$ \\
& S3 & $38(37 \%)$ & $7(8 \%)$ & $45(24 \%)$ & $40(38 \%)$ & $2(2 \%)$ & $42(22 \%)$ & $\chi^{2}=.103$ \\
& S4 & $12(12 \%)$ & $21(24 \%)$ & $33(17 \%)$ & $10(10 \%)$ & $25(29 \%)$ & $35(19 \%)$ & $\chi^{2}=.059$ \\
& S5 & $0(0 \%)$ & $2(2 \%)$ & $2(1 \%)$ & $2(2 \%)$ & $17(20 \%)$ & $19(10 \%)$ & $\chi^{2}=13.762 * * *$ \\
& S6 & $18(17 \%)$ & $21(24 \%)$ & $39(21 \%)$ & $19(18 \%)$ & $16(19 \%)$ & $35(19 \%)$ & $\chi^{2}=.216$ \\
& Total & $104(100 \%)$ & $86(100 \%)$ & $190(100 \%)$ & $104(100 \%)$ & $85(100 \%)$ & $189(100 \%)$ \\
& No response & N/A & 18 & 18 & N/A & 19 & 19 & \\
& S1 & $12(12 \%)$ & $7(8 \%)$ & $19(10 \%)$ & $10(10 \%)$ & $9(10 \%)$ & $19(10 \%)$ & $\chi^{2}=.000$ \\
& S2 & $12(12 \%)$ & $14(15 \%)$ & $26(13 \%)$ & $6(6 \%)$ & $9(10 \%)$ & $15(9 \%)$ & $\chi^{2}=2.951$ \\
& S3 & $36(35 \%)$ & $12(13 \%)$ & $48(24 \%)$ & $42(40 \%)$ & $4(5 \%)$ & $46(24 \%)$ & $\chi^{2}=.043$ \\
YA & S4 & $32(31 \%)$ & $11(12 \%)$ & $43(22 \%)$ & $19(18 \%)$ & $17(19 \%)$ & $36(19 \%)$ & $\chi^{2}=.620$ \\
& S5 & $1(1 \%)$ & $10(11 \%)$ & $11(6 \%)$ & $11(11 \%)$ & $39(44 \%)$ & $50(26 \%)$ & $\chi^{2}=24.934 * * *$ \\
& S6 & $11(11 \%)$ & $39(42 \%)$ & $50(25 \%)$ & $16(15 \%)$ & $10(11 \%)$ & $26(14 \%)$ & $\chi^{2}=7.579 * *$ \\
& Total & $104(100 \%)$ & $93(100 \%)$ & $197(100 \%)$ & $104(100 \%)$ & $88(100 \%)$ & $192(100 \%)$ & \\
& No response & N/A & 11 & 11 & N/A & 16 & 16 & \\
& S1 & $18(17 \%)$ & $6(8 \%)$ & $24(13 \%)$ & $19(18 \%)$ & $8(10 \%)$ & $27(14 \%)$ & $\chi^{2}=.176$ \\
& S2 & $13(13 \%)$ & $11(14 \%)$ & $24(13 \%)$ & $2(2 \%)$ & $21(25 \%)$ & $23(12 \%)$ & $\chi^{2}=.021$ \\
& S3 & $34(33 \%)$ & $6(8 \%)$ & $40(22 \%)$ & $38(37 \%)$ & $1(1 \%)$ & $39(21 \%)$ & $\chi^{2}=.013$ \\
TA & S4 & $15(14 \%)$ & $8(10 \%)$ & $23(13 \%)$ & $14(13 \%)$ & $16(19 \%)$ & $30(16 \%)$ & $\chi^{2}=.925$ \\
& S5 & $0(0 \%)$ & $7(9 \%)$ & $7(4 \%)$ & $10(10 \%)$ & $25(30 \%)$ & $35(19 \%)$ & $\chi^{2}=18.667 * * *$ \\
& S6 & $24(25 \%)$ & $42(53 \%)$ & $66(36 \%)$ & $21(20 \%)$ & $12(15 \%)$ & $33(18 \%)$ & $\chi^{2}=11.000 * *$ \\
& Total & $104(100 \%)$ & $80(100 \%)$ & $184(100 \%)$ & $104(100 \%)$ & $83(100 \%)$ & $187(100 \%)$ & \\
& No response & N/A & 24 & 24 & N/A & 21 & 21 &
\end{tabular}

Note. 1. S1: hint, S2: expression of annoyance or disapproval, S3: request for repair or forbearance, S4: explicit complaint, S5: accusation and threat, S6: opting out

2. $* * \mathrm{p}<.01 ; * * * \mathrm{p}<.001$

Status also seemed to have some effect on the young adult (YA) group's choices of complaint strategies $\left(\chi^{2}=\right.$ $36.069, \mathrm{p}<.001)$. Overall, towards superiors, they preferred opting out $(25 \%)$ and requests for repair $(24 \%)$, with the former being the most favored initiative $(35 \%)$ and the latter $(42 \%)$ being chosen most often as the response to the upgrader. However, their interactional pattern with status equals was different. Their overall 
selection reflected that they preferred accusations (26\%), with requests for repair being chosen with the highest frequency (40\%) to initiate the complaint and accusations for responding to the upgrader (44\%). Statistical analyses further showed significant differences between accusations and opting out. While the YA subjects were more likely to employ accusations towards status equals and strongly responded to the upgrader, they tended to opt out of complaining to superiors, and this led to the interpretation that they were more concerned with preserving face for superiors than for status equals.

The teenager (TA) subjects' complaint tendency was similar to the YA group to be more concerned with preserving face for their superiors than for status equals but with some differences. They chose opting out (36\%) most often in complaints towards superiors and also as their response to the offensive upgrader (53\%), whereas they preferred requests for repair (33\%) as the initiative. Their pattern with status equals was different, with requests for repair as the most favored strategy (21\%) in general and also as an initiative (37\%). As for their response to their peers' offensive upgrader, they were most likely to utilize accusations (30\%).

Summing up the findings, the MA subjects' interactional patterns with superiors and status equals appeared similar. Although the MA subjects were inclined to be slightly more indirect towards superiors than towards co-workers, their behavioral patterns towards the two types of addressees were similar, revealing their intention to protect face for colleagues as they did for superiors. This implies that differences in status did not exert as great an influence on the MA group's complaint strategies as it did on those of the YA and TA groups. However, in addition to explicit complaints, they also tended to be silent to the superior's upgrader. This suggests that these MA subjects may use stronger and severer strategies when their polite requests for repair are answered with an intensified utterance, but they were also likely not to persist in complaining to superiors, indicating their conservative attitude in the workplace, especially in interactions with the higher-status addressees.

The other two groups, the YA and TA groups, exhibited similar complaint patterns towards superiors and status equals - their overall strategy choices appeared to be severer towards status equals than towards superiors. In addition, when the two groups complained to superiors, they tended to initiate complaints with a request and were more likely to keep silent than use any other strategy to an offensive upgrader, but their response to the status equals' upgrader was much stronger. This could be because the members of these two groups were still students, and the teacher's authoritative status made them discreet about their speech. They might also have regarded keeping complaining to or arguing with the teacher as vain, which might only lead to the teacher's irritation and negative impressions on the complainer. In contrast, they might not have been as concerned about either politeness or their classmates' face and so tended to choose straightforward expressions of unhappiness. The two groups' straightforwardness towards status equals might also have reflected attempts to construct identities within their own groups. As Eckert (1997) has indicated, young people use non-standard variants as solidarity markers, and the use of direct expressions can have a similar function. Nonetheless, the TA subjects differed from the YA subjects in their preference for keeping silent in higher-status scenarios, and this revealed the TA subjects' greater tendency to suppress unhappiness to superiors than their YA counterparts.

In contrast to the MA group, social status appeared to contribute to a great difference in the complaint patterns of the YA and TA groups. They were much more indirect towards superiors than towards status equals. Compared with the MA subjects, Oliver's (1971) emphasis of Chinese people's respect for authority seemed to be more apparent in the YA and TA subjects' speech behavior. They were sensitive to their teachers' high status possibly not only because of the teacher's role as a knowledge transmitter but also because of the age difference between them and their teachers. In addition, the influence of the Chinese tradition, "zun shi zhong dao" (尊師重道), which refers to the respect that students should show to the teachers and what they teach, may have led these students to be more reserved in their complaints towards superiors. Nonetheless, they could be quite straightforward and even severe when complaining to classmates because they were members of the same community. The feeling of belonging to the same group might have made them feel that they could express their dissatisfaction to these classmates rather directly.

\subsection{Social Distance and Complaint Strategies}

Like status, the variable of social distance seemed to influence the subjects' choices of complaint strategies. As displayed in Table 5, the middle-aged (MA) subjects preferred requests for repair for addressees of three distance types (strangers: $28 \%$; siblings: $24 \%$; neighbors: $24 \%$ ), and they also favored hints (28\%) towards strangers and explicit complaints $(25 \%)$ towards siblings. However, their complaint sequences with these three types of addressees were different. Table 6 shows that their complaints towards strangers were likely to start with a request for repair (45\%), followed by an accusation (31\%) as a response to the upgrader. The sequence was similar towards neighbors, but the response was much milder, with disapproval (37\%) being employed most 
often. In contrast, the complaint pattern towards siblings was stronger in the severity tendency, using an explicit complaint (34\%) to initiate the sequence and an accusation (31\%) to respond to the upgrader. In short, they seemed to be severest towards siblings, followed by strangers, and finally neighbors, and Chi-square analyses further support this tendency.

Table 5. Raw Number, Percentage, and Chi-square Value of the Three Groups' Strategy Selection in Scenarios Involving Addressees of Three Distance Types

\begin{tabular}{|c|c|c|c|c|c|}
\hline Group & Strategy & $(+\mathrm{D})$ & $(-D)$ & $(\sim \mathrm{D})$ & Chi-square \\
\hline \multirow{8}{*}{ MA } & S1 & $55(28 \%)$ & $7(3 \%)$ & $17(9 \%)$ & $48.709 * * *$ \\
\hline & S2 & $11(6 \%)$ & $41(20 \%)$ & $37(20 \%)$ & $17.888 * * *$ \\
\hline & S3 & $55(28 \%)$ & $48(24 \%)$ & $61(32 \%)$ & 1.549 \\
\hline & S4 & $17(9 \%)$ & $50(25 \%)$ & $31(16 \%)$ & $16.796^{* * *}$ \\
\hline & S5 & $36(18 \%)$ & $35(17 \%)$ & $18(10 \%)$ & $6.899 *$ \\
\hline & S6 & $24(12 \%)$ & $23(11 \%)$ & $24(13 \%)$ & .028 \\
\hline & Total & $198(100 \%)$ & $204(100 \%)$ & $188(100 \%)$ & \\
\hline & No response & 10 & 4 & 20 & \\
\hline \multirow{8}{*}{ YA } & S1 & $32(17 \%)$ & $6(3 \%)$ & $9(5 \%)$ & $25.830 * * *$ \\
\hline & S2 & $18(9 \%)$ & $41(20 \%)$ & $43(22 \%)$ & $11.353 * *$ \\
\hline & S3 & $47(25 \%)$ & $47(23 \%)$ & $49(26 \%)$ & .056 \\
\hline & S4 & $25(13 \%)$ & $56(28 \%)$ & $30(16 \%)$ & $14.973 * *$ \\
\hline & S5 & $44(23 \%)$ & $32(16 \%)$ & $36(19 \%)$ & 2.000 \\
\hline & S6 & $25(13 \%)$ & $21(10 \%)$ & $25(13 \%)$ & .451 \\
\hline & Total & $191(100 \%)$ & $203(100 \%)$ & $192(100 \%)$ & \\
\hline & No response & 17 & 5 & 16 & \\
\hline \multirow{8}{*}{ TA } & S1 & $35(18 \%)$ & $8(4 \%)$ & $13(7 \%)$ & $22.107 * * *$ \\
\hline & $\mathrm{S} 2$ & $19(10 \%)$ & $40(20 \%)$ & $41(21 \%)$ & $9.260 * *$ \\
\hline & S3 & $51(26 \%)$ & $36(18 \%)$ & $56(29 \%)$ & 4.545 \\
\hline & S4 & $27(14 \%)$ & $63(31 \%)$ & $30(16 \%)$ & $19.950 * * *$ \\
\hline & S5 & $39(20 \%)$ & $44(22 \%)$ & $33(17 \%)$ & 1.569 \\
\hline & S6 & $23(12 \%)$ & $12(6 \%)$ & $19(10 \%)$ & 3.444 \\
\hline & Total & $194(100 \%)$ & $203(100 \%)$ & $192(100 \%)$ & \\
\hline & No response & 14 & 5 & 16 & \\
\hline
\end{tabular}

A similar pattern was found in the young adult (YA) and the teenager (TA) groups, but they tended to be severer towards strangers than the MA group. Among the six strategies, requests for repair were preferred towards strangers (YA: 25\%; TA: 26\%) and neighbors (YA: 26\%; TA: 29\%), and explicit complaints (YA: 28\%; TA: 31\%) were favored towards siblings. The two groups' complaint sequences towards strangers and neighbors were also similar, both with a tendency to start the complaint with a request for repair, followed by an accusation to respond to the upgrader. Chi-square analyses further demonstrate the two groups' similarity, with the highest severity towards siblings and slight differences in severity level of complaints used towards strangers and neighbors. However, their complaint sequence with siblings reveal some differences: although they were both most likely to begin with an explicit complaint, the YA group preferred disapproval (24\%) or an accusation (24\%) to come after the addressee's irritating upgrader whereas the TA group favored accusations (37\%).

In conclusion, the MA group's severity tendency and complaint sequence appeared to be different from those of the YA and TA groups. According to statistical analyses, the MA subjects tended to be severest towards siblings, then strangers, and they were least severe towards neighbors. The severity tendency was also reflected in their complaint sequence. This finding is different from Leech (1983) and more supportive of Wolfson's Bulge theory. Possibly because of closeness to their siblings, the MA subjects were likely to begin complaints with severe, explicit strategies. If they were responded to by an irritating statement, they were inclined to use even stronger and severer accusations to fight back. In their interactions with strangers, the subjects might be more polite than with siblings when beginning complaints with a request for repair, but they also replied to the addressee's upgrader with an accusation as their requests were not appropriately dealt with. 
Table 6. Raw Number and Percentage of the Three Groups' Strategy Selection as Initiatives and Responses in Scenarios Involving Addressees of Three Distance Types

\begin{tabular}{|c|c|c|c|c|c|c|c|}
\hline \multirow[b]{2}{*}{ Group } & \multirow[b]{2}{*}{ Strategy } & \multicolumn{2}{|l|}{$(+\mathrm{D})$} & \multicolumn{2}{|l|}{ (-D) } & \multicolumn{2}{|l|}{$(\sim \mathrm{D})$} \\
\hline & & Initiative & Response & Initiative & Response & Initiative & Response \\
\hline \multirow{8}{*}{ MA } & $\mathrm{S} 1$ & $34(33 \%)$ & $21(22 \%)$ & $5(5 \%)$ & $2(2 \%)$ & $14(13 \%)$ & $4(5 \%)$ \\
\hline & $\mathrm{S} 2$ & $1(1 \%)$ & $10(11 \%)$ & $24(23 \%)$ & $17(17 \%)$ & $6(6 \%)$ & $31(37 \%)$ \\
\hline & S3 & $47(45 \%)$ & $8(9 \%)$ & $32(31 \%)$ & $16(16 \%)$ & $55(53 \%)$ & $5(6 \%)$ \\
\hline & $\mathrm{S} 4$ & $5(5 \%)$ & $12(13 \%)$ & $35(34 \%)$ & $15(15 \%)$ & $7(7 \%)$ & $24(29 \%)$ \\
\hline & S5 & $7(7 \%)$ & $29(31 \%)$ & $4(4 \%)$ & $31(31 \%)$ & $2(2 \%)$ & $16(19 \%)$ \\
\hline & S6 & $10(10 \%)$ & $14(15 \%)$ & $4(4 \%)$ & $19(19 \%)$ & $20(19 \%)$ & $4(5 \%)$ \\
\hline & Total & $104(100 \%)$ & $94(100 \%)$ & $104(100 \%)$ & $100(100 \%)$ & $104(100 \%)$ & $84(100 \%)$ \\
\hline & No response & N/A & 10 & N/A & 4 & N/A & 20 \\
\hline \multirow{8}{*}{ YA } & $\mathrm{S} 1$ & $17(16 \%)$ & $15(17 \%)$ & $3(3 \%)$ & $3(3 \%)$ & $8(8 \%)$ & $1(1 \%)$ \\
\hline & S2 & $4(4 \%)$ & $14(16 \%)$ & $17(16 \%)$ & $24(24 \%)$ & $16(15 \%)$ & $27(31 \%)$ \\
\hline & S3 & $43(41 \%)$ & $4(5 \%)$ & $35(34 \%)$ & $12(12 \%)$ & $48(46 \%)$ & $1(1 \%)$ \\
\hline & $\mathrm{S} 4$ & $17(16 \%)$ & $8(9 \%)$ & $36(35 \%)$ & $20(20 \%)$ & $12(12 \%)$ & $18(20 \%)$ \\
\hline & S5 & $6(6 \%)$ & $38(44 \%)$ & $8(8 \%)$ & $24(24 \%)$ & $4(4 \%)$ & $32(36 \%)$ \\
\hline & S6 & $17(16 \%)$ & $8(9 \%)$ & $5(5 \%)$ & $16(16 \%)$ & $16(15 \%)$ & $9(10 \%)$ \\
\hline & Total & $104(100 \%)$ & $87(100 \%)$ & $104(100 \%)$ & $99(100 \%)$ & $104(100 \%)$ & $88(100 \%)$ \\
\hline & No response & N/A & 17 & N/A & 5 & N/A & 16 \\
\hline \multirow{8}{*}{ TA } & $\mathrm{S} 1$ & $20(19 \%)$ & $15(17 \%)$ & $3(3 \%)$ & $5(5 \%)$ & $10(10 \%)$ & $3(3 \%)$ \\
\hline & $\mathrm{S} 2$ & $5(5 \%)$ & $14(16 \%)$ & $20(19 \%)$ & $20(20 \%)$ & $15(14 \%)$ & $26(30 \%)$ \\
\hline & $\mathrm{S} 3$ & $43(41 \%)$ & $8(9 \%)$ & $26(25 \%)$ & $10(10 \%)$ & $51(49 \%)$ & $5(6 \%)$ \\
\hline & $\mathrm{S} 4$ & $15(14 \%)$ & $12(13 \%)$ & $43(41 \%)$ & $20(20 \%)$ & $9(9 \%)$ & $21(24 \%)$ \\
\hline & S5 & $7(7 \%)$ & $32(36 \%)$ & $7(7 \%)$ & $37(37 \%)$ & $3(3 \%)$ & $30(34 \%)$ \\
\hline & S6 & $14(13 \%)$ & $9(10 \%)$ & $5(5 \%)$ & $7(7 \%)$ & $16(15 \%)$ & $3(3 \%)$ \\
\hline & Total & $104(100 \%)$ & $90(100 \%)$ & $104(100 \%)$ & $99(100 \%)$ & $104(100 \%)$ & $88(100 \%)$ \\
\hline & No response & N/A & 14 & N/A & 5 & N/A & 16 \\
\hline
\end{tabular}

However, the MA subjects' complaints towards neighbors were intriguing because they responded to the upgrader with a less severe strategy (disapproval) than the one they used to initiate their complaint (request for repair). The severity level of requests for repair was originally viewed as higher than disapproval in this study since they directly referred to the addressee and the expected compensated action. However, as indicated in Hong (2009), indirect requests for repair may be viewed as carrying similarly low severity to hints or even more polite. From this viewpoint, the MA subjects' complaints towards neighbors started with a mild request, followed by slightly severer disapproval when the neighbor uttered the upgrader and thus appeared to treat neighbors more indirectly in comparison with interactions with siblings and strangers. This could be because these middle-aged subjects were under the influence of the Chinese tradition, “dun qin mu lin" (敦親睦鄰), which stresses the importance of being nice to the neighbors. In addition, Wolfson's Bulge theory, claiming speakers' uncertainty about the relationship with an acquaintance contributing to politeness and indirectness, can also explain this speech style. In other words, the MA subjects were inclined to be careful about their speech when interacting with neighbors, whom they know and meet once in a while but are uncertain about their relationships whereas they could be straightforward when complaining to siblings and strangers, whose relationships are rather certain.

The YA and TA subjects' complaints were not as indirect as those of the MA group in the same scenarios though they were also severest with siblings. However, the two groups' complaint sequences directed towards siblings were slightly different, with the TA group being stronger when responding to the sibling's upgraded responses. As assumed, the TA group's closeness to siblings may make them more straightforward and less concerned about whether what they said threatened the siblings' face or not. In contrast, the YA subjects' sequence reflected that they might react to the upgrader with a milder strategy than the one they used to initiate complaints. The difference between the two groups could result from most teenagers of traditional family in Taiwan living with their family but moving to a place close to the university they attend. The disengagement from family may lead to the YA subjects' lower familiarity level with their siblings and also a milder complaint tendency in comparison with the TA group.

\section{Conclusion}

This study investigates the selection of complaint strategies by middle-aged (MA), young-adult (YA) and teenage (TA) English users in Taiwan. It also divides the strategies into initiatives and responses to an offensive upgrader from the addressee. In general, the three groups' complaint sequences were similar - they all preferred requests for repair to initiate the complaint sequence and tended to use a severer strategy to respond to the upgrader. However, the MA group was the least severe among the three groups, and no significant differences 
were found between the YA and TA groups. This suggests not only that preferences for complaint strategies are affected by the subjects' age but also that there is a behavioral difference between students and people in employment. The age difference between the YA and TA groups was about 5-6 years old, but they were all students. Therefore, their relationships with family, teachers, and classmates were similar, and so were their attitudes and values. In contrast, the MA subjects were English teachers, who had been working for some years. They had become mature, especially under the influence of their working environment and the expectations surrounding them, thus leading to a lower complaint severity than the other two groups.

The main contribution of this study is that it reveals some general patterns in complaint behavior perceived as appropriate by English users in an EFL setting and further described age-related effects on perceptions of face-threatening speech behavior. The study found out that there were no obvious differences between teenagers' and college students' preferences. Contrary to other studies in the literature, the TA subjects of this study did not intentionally adopt particular speech styles to display their differences from other age groups or to establish solidarity. The MA subjects, on the other hand, exhibited an indirect speech style, which previous studies have indicated as the result of workplace pressure.

However, this study also had some limitations, which could be fruitfully addressed in future studies. For example, although all of the subjects were at least at an intermediate level of English proficiency, the MA subjects, who were English teachers, obviously had a higher proficiency than the other two groups. In Taiwan, an EFL setting, it is actually difficult to find middle-aged people with an intermediate level of English proficiency who are not working in English-related professions. However, if future researchers can overcome this difficulty and put together subjects from different age groups with truly equivalent levels of English proficiency, the age effects on the subjects' complaints can be explored without the interference from this variable.

In addition, a disproportionate number of the participants in this study were female. This was because a majority of students and teachers majoring in English in Taiwan are female. More male participants are needed for further investigations of the interactions of age and gender effects on complaint strategies. Finally, it is evident that age, status, and social distance are not the only three contextual variables that may influence a speaker's perceptions of appropriate complaints, but it would be far too complicated to include all variables, even the interactions of these variables, in the scenarios. Future studies can address different variables and their impacts on different age groups' complaint styles so as to offer a fuller picture of English users' complaints.

\section{Footnotes}

[1] An earlier version of this research study was presented at American Association for Applied Linguistics (AAAL) 2011 Conference.

[2] Participants of this study had taken General English Proficiency Test (GEPT) or Test of English for International Communication (TOEIC) before. They either had passed the intermediate level GEPT or had achieved a TOEIC score higher than 650 .

[3] The scenarios of superiors and status equals for the middle-aged subjects were different from those for the other two groups. These scenarios were modified to situations that include an employer or a co-worker to replace teachers and classmates in the original version. The other scenarios remained the same.

\section{References}

Bachman, L., \& Palmer, A. (1996). Language Testing in Practice. Oxford: Oxford University Press.

Blum-Kulka, S. (1982). Learning to say what you mean: A study of speech act performance of learners of Hebrew as a second language. Applied Linguistics, 3, 29-59.

Brown, P., \& Levinson, S. (1987). Some universals in language usage. Cambridge: Cambridge University Press.

Brown, R. W., \& Gilman, A. (1960). The pronouns of power and solidarity. In T. Sebeok, (Ed.), Style in language (pp. 253-276). Cambridge, MA: M.I.T. Press.

Chambers, J., \& Trudgill, P. (1980). Dialectology. London: Cambridge University Press.

Chang, S. - - L. (2006). The speech act of complaining in mandarin Chinese: Perceptions and productions among four age groups. Unpublished Master's thesis, National Kaohsiung Normal University, Kaohsiung, Taiwan.

Cohen, A., \& Shively, R. (2007). Acquisition of requests and apologies in Spanish and French: impact of study abroad and strategy-building intervention. Modern Language Journal, 91, 189-212.

Clyne, M. (1994). Inter-cultural communication at work: Cultural values in discourse. Cambridge: Cambridge University Press.

D’ Amico Reisner, L. (1985). An ethnolinguistic study of disapproval exchanges. Unpublished PhD dissertation, 
University of Pennsylvania.

DeCapua, A. (1988). Complaints: A comparison between German and English. Unpublished manuscript. Bronxville, NY: Concordia College, English Language Center.

Eckert, P. (1997). Age as a sociolinguistic variable. In: F. Coulmas (Ed.), The handbook of sociolinguistics (pp. 151-167). MA: Blackwell Publishing Company.

Edmondson, W., \& House, J. (1981). Let's talk and talk about it. Munchen: Urban and Schwarzenberg.

Hofstede, G. (1984). The cultural relativity of the quality of life concept. Academy of Management Review, 9(3), 389-398.

Hong, C. -Y. (2009). An interlanguage pragmatic study of complaints made by Chinese learners of English in Taiwan. Unpublished doctoral dissertation, National Kaohsiung Normal University, Kaohsiung, Taiwan.

Horvath, B. (1985). Variation in Australian English: The sociolects of Sydney. Cambridge: Cambridge University Press.

Hudson, T., Detmer, E., \& Brown, J. (1995). Developing prototypic measures of cross-cultural pragmatics (Technical Report \#7). Honolulu: University of Hawai'i, Second Language Teaching and Curriculum Center.

Labov, W. (1966). The social stratification of English in New York City. Washington, D. C.: Center for Applied Linguistics.

Lee, J. S. (1999). Analysis of pragmatic speech styles among Korean learners of English: A focus on complaint-apology speech act sequence. Unpublished doctoral thesis, Stanford University. (UMI No. 9961914)

Leech, G. (1983). Principles of pragmatics. London: Longman.

Lu, L., \& Kao, S.-F. (2002). Traditional and modern characteristics across the generations: Similarities and discrepancies. The Journal of Social Psychology, 142(1), 45-59.

Marriott, H. (1995). The acquisition of politeness patterns by exchange students in Japan. In B. F. Freed (Ed.), Second language acquisition in a study abroad context (pp. 197-224). Amsterdam: Banjamins.

Murphy, B., \& Neu, J. (1995). My grade's too low: The speech act set of complaining. In S. M. Gass \& J. Neu (Eds.), Speech acts across cultures (pp. 191-216). Berlin: Walter de Gruyter \& Co.

Oliver, R. (1971). Communication and culture in ancient India and China. New York: Syracuse.

Olshtain, E., \& Weinbach, L. (1993). Interlanguage features of the speech act of complaining. In S. M. Kasper \& S. Blum-Kulka (Eds.), Interlanguage pragmatics (pp. 108-122). New York: Oxford University Press.

Regan, V. (1995). The acquisition of sociolinguistic native speaker norms: Effects of a year abroad on second language learners of French. In B. F. Freed (Ed.), Second language acquisition in a study abroad context (pp. 177-201). Amsterdam: Banjamins.

Shea, H. K. (2003). Japanese complaining in English: A study of interlanguage pragmatics. Unpublished doctoral thesis, Columbia University. (UMI No. 3091292)

Shih, Y. H. (1999). Conversational politeness and foreign language teaching. Taipei: The Crane Publishing Co., Ltd.

Tagliamonte, S. (2005). So who? Like how? Just what? Discourse markers in the conversations of young Canadians. Journal of Pragmatics, 37, 1896-1915.

Trosborg, A. (1995). Interlanguage pragmatics: Requests, complaints, and apologies. Berlin: Walter de Gruyter $\&$ Co.

Trudgill, P. (1974). The social differentiation of English in Norwich. Cambridge: Cambridge University Press.

Wardhaugh, R. (2002). An introduction to sociolinguistics ( $4^{\text {th }}$ ed.). Malden, MA: Blackwell Publishing.

Warga, M., \& Scholmberger, U. (2007). The acquisition of French apologetic behavior in a study abroad context. Intercultural Pragmatics, 4(2), 221-251.

Wolfson, N. (1988). The bulge: A theory of speech behavior and social distance. In J. Fine (Ed.), Second language discourse: A textbook of current research (pp. 21-38). Norwood, NJ: Ablex.

\section{(cc) EY}

This work is licensed under a Creative Commons Attribution 3.0 License. 